\title{
THE YOUNG PLASMA CELL OR LYMPHOCYTE IN CHRONIC INFLAMMATION.
}

\author{
By Major H. Herbert, F.R.C.S., I.M.S. \\ From the Pathological Laboratory, University Collegc, Victoria University, Liveryool.
}

\section{(Plate V.)}

In working recently at the pathology of trachoma the examination of the tissues employed brought prominently forward some facts, partly or altogether new, of general importance and application. Besides a number of human conjunctivæ, normal and inflamed, at ages ranging from birth upwards, cat's and guinea-pig's conjunctivæ, and both human and other intestinal mucous membrane and lymphatic glands, were made use of, prepared both by common histological methods, and more particularly by Unna's methods of protoplasm-staining. The matters of general interest are the following:-

$A$ demonstration of the transition from ordinary connective tissue to normal adenoid tissue, and from this onward to granulation or chronic inflammatory tissue - normal adenoid tissue representing a midway stage between the other two tissues. Normally, the greater portion of the human conjunctiva of the lids and retrotarsal folds is adenoid and glandular in structure, the rest of the membrane forming simply a smooth moist surface, adapted for friction, consisting of epithelium alone or of epithelium covering areolar tissue. The adenoid tissue often, but not always, contains small lymph follicles and nodules or "lymph heaps." In the cat's and guinea-pig's conjunctiva there is very little adenoid tissue; a complete section of guinea-pig's membrane shows merely a strip of this tissue occupying one fornix. A number of sections through the lower fornix of a human infant at birth contain no definite adenoid tissue; only here and there may be found a group of small round cells, possibly representing the earliest beginnings of lymphoid follicles. The conjunctiva from an infant of three months, on the other hand, contains fairly well-developed lymphoid tissue. A comparison of these various membranes in their different parts, when prepared by Unna's protoplasm-staining methods, shows clearly the development of adenoid from ordinary connective tissue. The change consists in the cellular elements becoming much more numerous, and 
very many of them altered from fixed connective tissue cells into plasma cells "and small round cells or lymphocytes, a large proportion of the latter being massed in follicles and nodules, where they are proluced in large numbers. It is important to recognise at the outset that these small cells are essentially young plasma cells, the "daughter plasma cells" of Unna, derivatives of fixed connective tissue cells. Careful staining brings out, in all but the very smallest of them, the characteristic nuclei, and the larger ones have dark rings of protoplasm; and there are transition cells between them and the large typical plasma cells distributed through the membrane, and also between them and fixed connective tissue cells. Their small size and scanty protoplasm is explained by their rapid division, shown by the very large number of cells ${ }^{2}$ undergoing mitosis scattered anong them in the follicles and nodules. Besides the above cells, there are found throughout the conjunctiva a few polyuuclear leucocytes, and especially in the areolar tissue of the non-lymphoid portions and of the submucous nembrane a number of "mast cells," coarsely granular basophile.

In various chronic congestions of the conjunctiva, and in follicular conjunctivitis and trachoma, besides an increase in the number of cells ${ }^{3}$ distributed through the membrane, there is a hypertrophy of existing follicles and lymph heaps, and a new formation of these structures. Many of the new formations display a departure from normal in a deficiency of supporting stroma and of blood vessels, which lie in the stroma. The deficiency is seen in two stages-(1) At the spreading margin of a follicle (Plate V. Fig. 1) are columns of cells distending lymph spaces; the stroma no longer penetrates between the individual cells. (2) More especially in the severer forms of follicular conjunctivitis and in trachoma are found rounded collections of very small Iymphocytes, ${ }^{4}$ with a few larger mitotic plasma cells among them lying quite free in lymph vessels, and sharply encapsuled by the vessel walls. The small size of these cells, fed by a very abundant supply of lympb, probably indicates unusually rapid inultiplication. One such collection, situated well away from others similar, may, it appears, by continued growth, uitimately give rise to a follicle, which must in this case be devaid of supporting stroma and of blood vessels, and must be

\footnotetext{
'Unna's plasma cells are the rounded cells, modificd from hxed connective tissue cells in chronic inflammation. The nuclei are round or oval, and have comparatively large separate iumps of chromatin; the protoplasm stains deeply with basic dyes, retaining the dye, on over-staining and special decolorising, after it has mostly left the nuelei.

"These swollen cells have been at times spoken of as "epithelioid."

3 Fspecially large typical plasma cells in mild chronic affections; and small cells, together with an infiltration of polynuclear lencocytes, in acute and suhacute inflanmations.

The small lymphocytes in these amall early collections are not definitely characteristic in nuclei, and have practically no protoplasm to stain. They can only be recognised as of connective tissue origin by $(a)$ the invoriable presence among them of one or more larger mitotic plasma cells, by $(b)$ the fact that these plasma cells may oceasionally be seen ta arise by modification of the endothelia of the lymph vessel wall, and by (c) the very numerous gradations in size and appearance between these smallest cells and the older fully characteristic cells in and about large follicles.
} 
completely encapsuled. More commonly the follicles are made up by continued additions of cells grouped in lymph spaces and lymph vessels, and are imperfectly vascularised and also incompletely encapsuled.

A trachoma follicle consisting almost entirely of young cells, the product of comnective tissue cells, is one of the purest examples of chronic inflammatory tissue. The granulation tissue of wounds and ulcers, granulomata, etc., contains a varying proportion of leucocytes and remains of original connective tissue. The normal adenoid conjunctiva differs from the chronic trachomatous, chiefly in its larger proportion of supporting tissue, white fibrous and elastic, carrying blood vessels. It may be said that the adenoid tissue of lymphatic glands and mucous membranes, exposed to more or less constant irritation from micro-organisms and their products, shows the constant presence and very ready proliferation of the plasma cell in all its stages and changes, which is found in the more protected connective tissues, only under a much more definite inflammatory stimulus.

Mitosis in plasma cells is especially well studied in trachoma follicles, since there may be no other cells but plasma cells present. When the mitotic figures are fully formed, the protoplasm no longer stains with basic dyes, and so neither nucleus nor protoplasm remains characteristic; hence mitosis in plasma cells has not been clearly demonstrated hitherto. The swollen cells in lymph- and trachomafollicles, preparing for division, with nuclei showing only a few large rounded lumps of chromatin, probably altered by fixing reagent, have often a considerable quantity of darkly stained protoplasm.

The mass of cells in a trachoma follicle soon outgrows its food supply; the cells cease to multiply, and break down both by colliquative and hyaline degeneration, and the debris is carried away by the lymphatics. Many other cells probably pass away whole in the lymph stream, as from normal adenoid tissue. But what I especially wish to notice is another means of removal which comes into play in these chronically inflamed membranes at quite an early stage.

Amaboid activity of lymphocytes.-Lymphocytes are commonly classed as non-amceboid. In chronic trachoma and follicular conjunctivitis, however, many of these young cells distributed through the membrane are stimulated into active movement. The nuclei stain darkly and uniformly, while the thin coverings of protoplasm are no longer visible with basic dyes. The softened pliable cells stretch out along the tissue spaces, often into long threads, accommodating themselves to the passages by which they travel away. These cells are not seen to any extent within the follicles, but are rather between the follicles and in the surface epithelium. They are sometimes clustered very thickly just without one portion of the margin of a follicle; for instance, at the opposite margin ${ }^{1}$ of the follicle whose one border is

\footnotetext{
${ }^{I}$ It is noteworthy that mitoses, which are thickly grouped about the spreading margin of this follicle, seen in the figure, are absent from the neighbourhood of the amœboid cells.
} 
seen in Plate V.Fig. 1. Practically all the cells are becoming amœboid, travelling away, many of them toward and through the surface epithelium.

The amœboid transformation of lymphocytes can be especially well studied in sections of large palpebral papille, which represent an occasional later development ${ }^{1}$ of trachoma follicles. Here the lymphocytes are comparatively few in number and rather large, separated by thick bundles of connective tissue fibres, and possibly their amœboid activity is not very great. Pear-shaped and tailed nuclei may be found, the thicker unchanged, and still containing a nucleolus and separate dots of chromatin (Plate V. Fig. 2). So far as my specimens show, a decidedly active amœboid contractility is not found in the lymphocytes of the normal conjunctiva; one does not see the uniformly dark elongated nuclei of the chronically inflamed membranes. Yet lymphocytes are distributed through the epithelium covering lymph follicles, and may occasionally be seen in the walls of small blood vessels (see below). Unless these cells be endowed with some slight independent power of movement, it is difficult to see how they attain their position.

I have sections from a case of old granular lids, with considerable, possibly recent, vascular injection, which show lymphocytes embedded in mucus on the surface of the membrane, side by side with a few polynuclear leucocytes. They still retain their individuality after their passage through the epithelium, with spherical nuclei and very scanty protoplasm, quite distinct from the polynuclear blood cells. Some of the nuclei close to the epithelium have separate dots of chromatin, while others further away are swollen and pale, evidently degenerating.

The passage of lymphocytes directly into small blood vessels. - It has often been supposed that the small-celled infiltration of inflammations, the "cells of repair," otherwise lymphocytes or daughter plasma cells, came from the blood vessels. Some of my specimens are very important in demonstrating exactly the opposite movement in these young cells, namely, their entry into the blood stream directly from the tissues through the walls of small veins. In Plate V. Fig. 3, are seen three cells lying in the wall of a venous radicle, which is passing through a lymph nodule. That they are passing inwards, and not outwards, is indicated by the fact that the vessel lies in a tissue which produces these cells in abundance, and by the fact that the thin films of vessel wall between the cells and the blood stream are pressed inwards; this could scarcely be the case if the lymphocytes were travelling outwards. The section from which Plate V. Fig. 4 is taken is much more conclusive. The vessel wall is crowded with typical amoboid lympho-

The young cells are in process of formation about one margin, and pass away from the opposite margin of the follicle.

${ }^{1}$ See a paper "Changes in the Conjunctiva produced by Chronic Inflammation," Trans. Ophth. Soc. U. Kingdom, London, 1898-99. 
cytes, as is also the adjoining tissue. This vein is not situated in a lymph follicle or nodule, but among large plasma cells and actively moving young cells. Though some of the lymphocytes in the blool within the vein have the ordinary rounded form, many are still elongated and stretched out in a way that could not be brought about in the blood, but only in the tissue spaces through which they have passed. See especially one of the cells $b$, in the illustration; it was impossible to focus at the same time most of the cells in the blood with those in the vessel wall.

Note.-Though the above facts relate mostly to the human conjunctiva, this is simply because the number and variety of other tissues examined were not sufficient to render a very extended application at once possible. But there is no reason to suppose that ample corroboration may not be obtained in other adenoid tissue wherever situated.

\section{DESCRIPTION OF PLATE V.}

FIG. 1.-Spreading margin of a follicle in follicular conjunctivitis. - Cells arranged in columns distending lymph spaces. A, follicle; B, layers of large plasma cells; C, surface epithelium.

FrG. 2.-Amoeboid lymphocytes.-Section of a palpebral papilla. A, mass of epithelial cells, portion of an epithelial down-growth ; (a) tailed lymphocyte, becoming amoeboid, thicker end of nucleus still showing nucleolus and separste chromatin dots; $(b)$ amocboid cell, long nucleus, with a very faint tail of protoplasm at its lower end ; $(c)$ amoeboid cells, one rather out of focus, lying in epithelium.

Fig. 3.-Lymphocytes in the wall of a venous radicle.-Situated in a lymph nodule; normal adult conjunctiva. The lymphocytes $a, a$, are separated from the lumen of the vessel by thin films of tissue, which are pressed inwards. The cell $a^{\prime}$ is similarly situated, but is rather out of focus, as is also a portion of the film between it and the vessel lumen. Lymphocytes and leucocytes within the vein; red blood cells unstained, not seen.

Fra. 4.-Amaboid lymphocytes in blood and vessel wall.-A smail vein in chronically inflamed conjunctiva; elsewhere trachoma follicles. $(a, a, a, a)$ amceboid lymphocytes in vessel wall, many others out of focus, not seen; $(b)$ lymphocytes escaping from the vessel wall into the blood, one of them clearly focussed; $(c, c)$ lymphocytes in the blood, more or less out of focus, still stretched out after their passage through tissue spaces; $(d)$ red blood cells. 


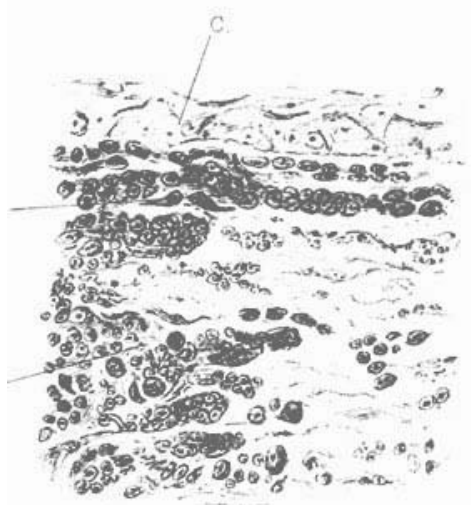

Fig. 1.

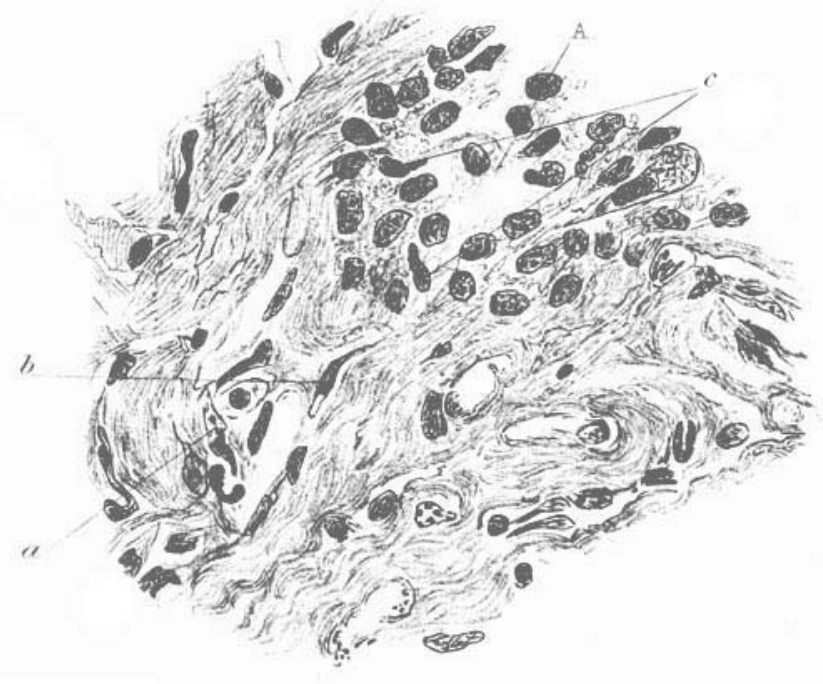

Fig. 2

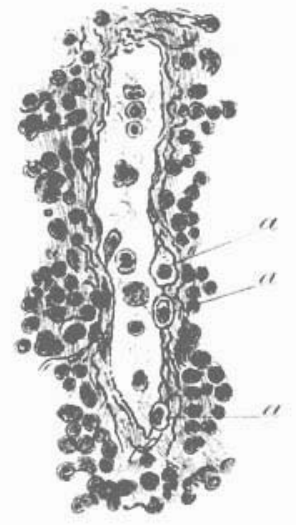

Fig 3

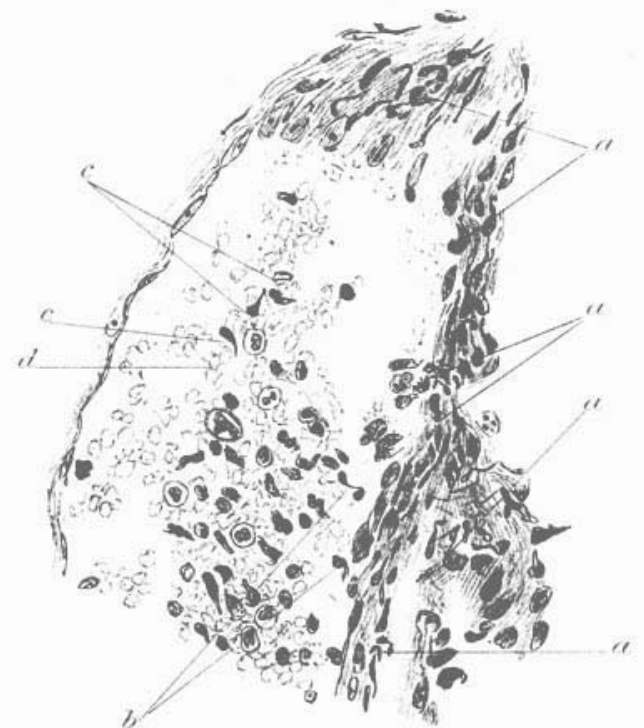

Fig. 4 . 